\title{
Characteristics of bacterial pathogens associated with acute diarrhea in children under 5 years of age: a hospital-based cross-sectional study
}

Lei Tian, Xuhui Zhu, Zhongju Chen, Weiyong Liu, Song Li, Weiting Yu, Wenqian Zhang, Xu Xiang and Ziyong Sun ${ }^{*}$

\begin{abstract}
Background: Acute diarrhea is a leading cause of morbidity and mortality in children, particularly in those under the age of 5 years. Rotavirus is recognized as the leading cause of acute diarrhea in children, however, the contribution of bacterial pathogens as causative agents varies throughout the world. Here we report a hospital-based prospective study to analyze the characteristics of bacterial pathogens associated with acute diarrhea in children under 5 years of age.
\end{abstract}

Methods: Stool samples were collected from 508 patients with acute diarrhea under 5 years of age who presented at our hospital. Nine pathogens were isolated and identified by culturing, serology or PCR, these included Salmonella spp., Shigella spp., Vibrio cholerae, diarrheagenic Escherichia coli (DEC), Aeromonas spp., Plesiomonas spp., Vibrio parahaemolyticus, Campylobacter spp. and Yersinia enterocolitica. Antimicrobial sensitivity tests of these pathogens were conducted. The most commonly detected pathogen, Salmonella spp., was further investigated by PCR and sequencing of antibiotic resistance-related genes.

Results: Pathogens were identified in $20.1 \%$ of the 508 samples. The most commonly detected pathogens were Salmonella spp. (8.5 \%), followed by DEC (4.7\%), Campylobacter jejuni (3.0 \%) and Aeromonas spp. (2.0 \%). The resistance rates to ampicillin and tetracycline in Salmonella spp. were $>60 \%$, but were $<30 \%$ to cephalosporins and quinolones. More than $50 \%$ of DEC strains displayed resistance to ampicillin, cefotaxime and tetracycline, and $60 \%$ of C. jejuni strains were resistant to ciprofloxacin but highly sensitive to the other antibiotics. Among 12 cephalosporin-resistant Salmonella isolates, TEM-1 and CTX-M-14 determinants were present in two (16.7 \%) isolates. PCR screening for plasmid-mediated quinolone resistance genes revealed gyrA mutations in one of three highly quinolone resistant isolates.

Conclusions: Salmonella spp., DEC, Campylobacter spp. and Aeromonas spp. were the most commonly detected bacterial pathogens in children under the age of 5 years with acute diarrhea. Our findings indicate that ampicillin and tetracycline are not suitable as first line therapeutic drugs against Salmonella spp. Resistance to third generation cephalosporins and quinolones was also detected. TEM-1 and CTX-M-14 genetic determinants, and gyrA mutations, were the major mechanisms associated with high levels of cephalosporin and quinolone resistance, respectively, in Salmonella isolates.

Keywords: Acute diarrhea, Antibiotic resistance, Bacterial pathogens, Young children

\footnotetext{
* Correspondence: zysun@tjh.tjmu.edu.cn

Department of Clinical Laboratory, Tongji Hospital, Tongji Medical College,

Huazhong University of Science and Technology, Wuhan, China
} 


\section{Background}

Diarrhea is one of the leading causes of morbidity and mortality in children under the age of 5 years worldwide, especially in developing countries such as sub-Saharan Africa and south Asia according to the report of the Global Enteric Multicenter Study (GEMS) [1]. Indeed, pediatric diarrhea accounts for $>800,000$ deaths per year globally (approximately $11 \%$ of the 7.6 million estimated annual global child deaths) [2, 3]. Targeted interventions are important for reducing diarrhea-associated morbidity and mortality. The GEMS was conducted to ascertain clinical and epidemiological data of moderate-to-severe diarrhea in children aged 0-59 months [4-7]. Although China is one of the 15 high-incidence countries, unfortunately, it was not included in the GEMS study.

The main cause of acute diarrhea in children is infectious organisms, including viruses, bacteria and parasites $[1,2]$. Along with improvements in living standards and health conditions, the incidence of parasite infections has decreased, with viruses and bacteria now being predominantly responsible for acute diarrhea in children [1, 2]. Human rotavirus is a major causative agent of diarrhea in children, especially in those $<5$ years of age. Most reports worldwide agree that rotavirus is the primary cause of acute diarrhea in children [2, 8-10]. However, the etiology of bacteria causing diarrhea appears to differ depending on geographical area. For example, a report from Spain indicated that Campylobacter spp. and Salmonella spp. were the primary bacterial pathogens, accounting for $22.2 \%$ and $16.4 \%$ of cases of acute diarrhea in children, respectively [11]. In Ecuador, Shigella spp. and Campylobacter jejuni were reported to be the main etiological causes of diarrhea [9]. Whereas in Turkey, Salmonella spp. (25.6\%) and C. jejuni (18.3\%) were the main causes of acute gastroenteritis in children [12].

China covers a large geographical area and due to the different levels of economic development between regions, significant differences exist in the causes of infectious diarrhea in children. According to a report by XinWang et al., a significant difference in the etiology of bacterial diarrhea existed between children in developing and developed regions of China [13]. The detection rate of Shigella spp. was 89 times higher in the developing region (county Sui, Henan province) than in the developed region (Beijing, the capital of China) studied in their report [13]. To date, few data have been reported on the etiology of acute diarrhea in children in central China.

Wuhan is the capital city of Hubei province, located in the middle of central China. Tongji hospital, which has more than 4000 beds, is the largest teaching hospital in central China, located in Wuhan, and treats patients from the six surrounding provinces (Xiangxi, Henan,
Hubei, Hunan, Anhui and Jiangxi). Our study analyzed fecal samples from 508 children, under 5 years of age, who presented with acute diarrhea at Tongji hospital (Fig. 1).

\section{Methods \\ Case recruitment}

Acute diarrhea was defined as three or more liquid, loose, mucus, or bloody stools within $24 \mathrm{~h}$, lasting no longer than 14 days. Persistent diarrhea was defined as diarrhea that lasted for more than 14 days at presentation $[14,15]$. Patients with persistent diarrhea were excluded from this study. Fever was defined as a temperature of $\geq 37.5^{\circ} \mathrm{C}$. If the parents or legal guardians accepted participation in the study, children under 5 years of age with acute diarrhea who were outpatients at our hospital were selected. Demographic information for each patient, including age, sex, address and clinical symptoms, was collected.

\section{Sample collection and microbiological methods}

From May 2014 to Aug 2015, samples were collected consecutively from patients whose parents or legal guardians agreed to take part in the study. All of the parents or guardians of the patients signed the informed consent. A stool sample was collected, prior to treatment with any prescribed antibiotics. A sterilized cotton swab was dipped in the mucus, purulent or bloody part of the stool sample, then immediately placed in CaryBlair Medium (Oxoid, United Kingdom). The samples were sent to the laboratory for immediate testing. In the laboratory, samples were cultured in different media to detect nine bacteria, these included Salmonella spp., Shigella spp., Vibrio cholerae, diarrheagenic Escherichia coli (DEC), Aeromonas spp., Plesiomonas spp., Vibrio parahaemolyticus, Campylobacter spp. and Yersinia enterocolitica. Xylose lysine deoxycholate medium (XLD), MacConkey agar (Mac) and thiosulfate-citrate-bile saltssucrose (TCBS) agar were used to isolate the pathogens conventionally (with the exception of Campylobacter). To further characterize Salmonella spp., sulfa enrichment broth (SBG) (Qingdao HopeBio-Technology, China) was used to enhance growth of the bacterium. Cefoperazone deoxycholate agar (CCDA) and Skirrow's medium were used to culture Campylobacter spp. in a microaerophilic environment at $42{ }^{\circ} \mathrm{C}$. Phosphate buffered saline (PBS) was used for the incubation of Yersinia enterocolitica to increase the bacterium concentration over 10 days at $4{ }^{\circ} \mathrm{C}$.

Strains that could not be easily identified were further investigated by manual biochemical reaction methods and/or instruments (VITEK-2 COMPACT, Biomerieux, France). Suspected Campylobacter colonies were subjected to PCR analysis to confirm the 


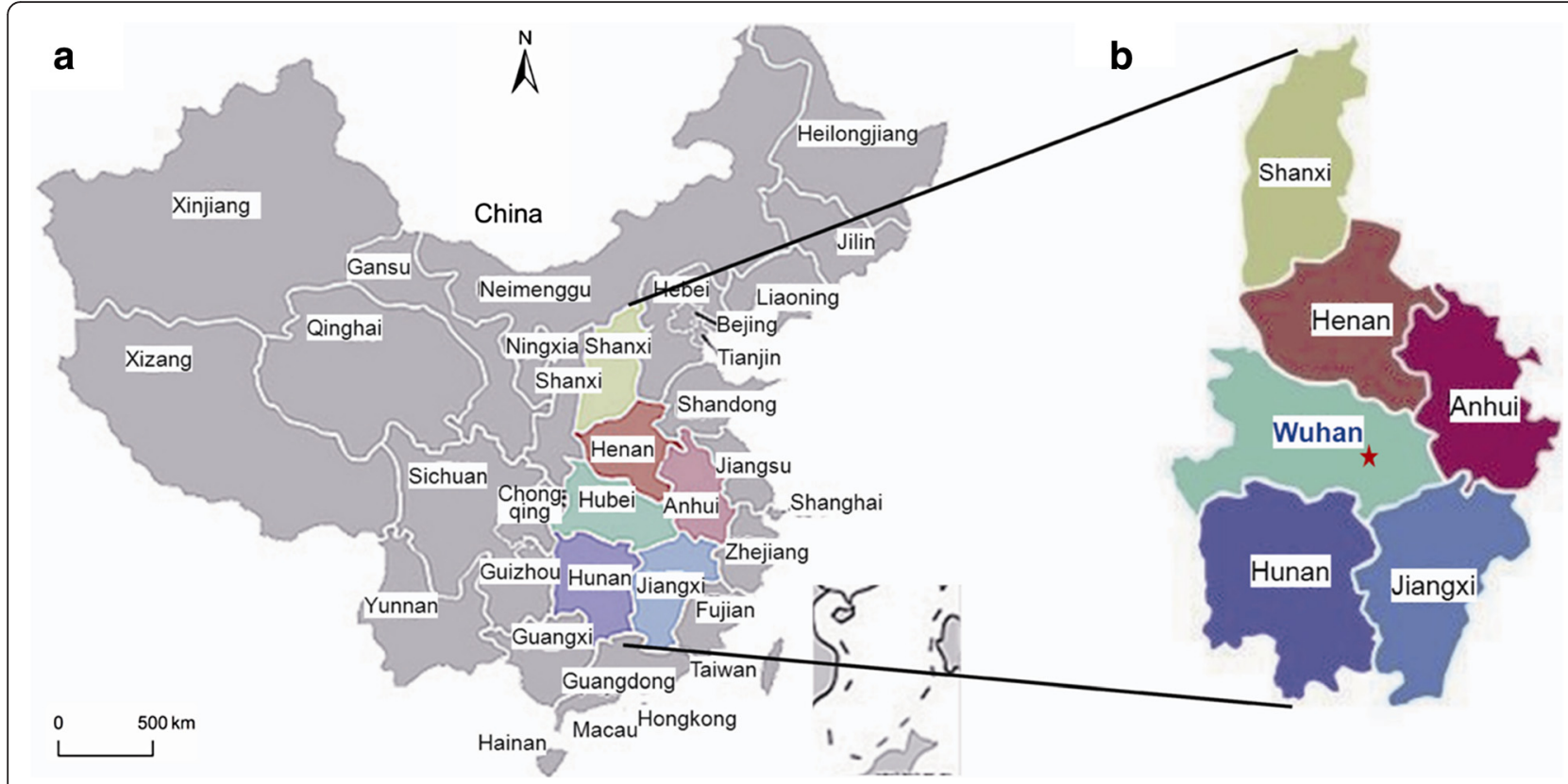

Fig. 1 a the map of China. $\mathbf{b}$ the location of certral China, including six provinces, Shanxi, Henan, Anhui, Hubei, Hunan and Jiangxi

identification, using a method previously reported by Denis et al $[16,17]$.

Serotype identification was carried out by slide agglutination tests for Salmonella spp., Shigella spp. and Vibrio cholerae (using Salmonella, Shigella spp. and V. cholerae O1, 0139 antiserum Diagnostic Antisera Kit, from Lanzhou Institute of Biological Products Co., Ltd. Lanzhou, China). Five distinct classes of diarrheagenic Escherichia coli (DEC) are recognized as being associated with diarrheal disease: enteropathogenic E. coli (EPEC), Shiga toxin-producing $E$. coli (STEC), enteroaggregative E. coli (EAEC), enteroinvasive E. coli (EIEC) and enterotoxigenic E. coli (ETEC). PCR was used to distinguish these E. coli pathotypes by amplification of the following gene targets: typical EPEC (eae and $b f p$ ), atypical EPEC (eae or $b f p$ ), STEC (eae and stx1 and/or stx2), ETEC (elt and/or estIa or estIb), EIEC (invE and ipaH) and EAEC (aggR and/or pic or astA) [18, 19].

\section{Antibiotic resistance testing}

To test antibiotic resistance in Campylobacter spp., the broth microdilution method was used with $5 \%$ sheep blood. For all other pathogens, antimicrobial susceptibilities were determined by the agar dilution method according to the Clinical and Laboratory Standards Institute (CLSI) Guidelines, 2015 [20]. All isolates of Salmonella spp. were tested for their minimum inhibitory concentrations (MICs) of ampicillin, ampicillin-sulbactam, ceftriaxone, cefotaxime, nalidixic acid, ciprofloxacin, levofloxacin, co-trimoxazole, azithromycin, chloramphenicol and tetracycline (Oxoid); DEC were tested for ampicillin, ampicillin-sulbactam, cefotaxime, ciprofloxacin, levofloxacin, chloramphenicol, tetracycline, cefazolin, cefuroxime, imipenem, amikacin and gentamicin (Oxoid); Campylobacter spp. were tested for ciprofloxacin, azithromycin, tetracycline, erythromycin and doxycycline (Oxoid); and Aeromonas spp. were tested for cefotaxime, ciprofloxacin, levofloxacin, co-trimoxazole, chloramphenicol, tetracycline, cefazolin, cefuroxime, imipenem, amikacin and gentamicin (Oxoid). ATCC 25922, 35218, 700603 and 27853 were used as quality control strains. Antibiotic susceptibility was interpreted according to CLSI guidelines, 2015 [20].

\section{Molecular characterization of antibiotic resistance genes of Salmonella spp. to cephalosporins and quinolones}

Those strains showing significantly decreased susceptibility to ceftriaxone and cefotaxime ( $\mathrm{MIC} \geq 32 \mathrm{mg} / \mathrm{Ml}$ ) were further studied by PCR amplification and sequencing of the extended-spectrum $\beta$-lactamase genes (ESBLs, including blaSHV, blaTEM and blaCTX-M). Those isolates showing high resistance to quinolones ( $\mathrm{MIC} \geq 32 \mathrm{mg} / \mathrm{mL}$ to ciprofloxacin or levofloxacin) were further tested for amino acid changes in the plasmid-mediated quinolone resistance genes gyrA and gyrB by PCR and sequencing, according to the methods reported by Yenkao et al [21]. The DNA sequences were compared with sequences in the GenBank database (http://www.ncbi.nlm.nih.gov/ genbank/) and the $\beta$-lactamase classification system (http://www.lahey.org/studies/) to confirm the subtypes of the $\beta$-lactamase genes. 


\section{Statistical analysis}

The chi-squared $\left(x^{2}\right)$ test was used to determine the statistical significance of the data by the software PASW Statistics 18.0 (IBM Corporation, New York). A P-value of $<0.05$ was considered statistically significant.

\section{Results}

\section{Clinical features}

During the data collection period (2014.5.1-2015.8.31), a total of 508 children aged 0-59 months who visited our hospital as outpatients were recruited to this study. Of the children, 295 (58.1\%) were male and 213 (41.9\%) were female. All of the parents or legal guardians of the patients agreed to participate in the study. A fecal specimen was collected from each patient. Blood and mucus were uncommon in the feces $(1.0 \%$ and $3.7 \%$, respectively). Of the 508 patients, $64.76 \%(329 / 508)$ were infants (0-11 months), $22.24 \%(113 / 508)$ were toddlers (12-23 months), and the other $12.99 \%(66 / 508)$ were children (24-59 months). Fever and vomiting were the main symptoms accompanying acute diarrhea. Up to $57.9 \%(294 / 508)$ of patients stayed in hospital for 1-3 days. There was a significant difference in the duration of diarrhea across the three age groups in the all studied pathogens (chi-squared test, $p<0.05$ ), whereas no significant difference was observed in the duration of diarrhea and symptoms across the three age groups with Salmonella infection (chi-squared test, $p>0.05$ ).

\section{Occurrence of pathogens}

In total, 102 strains of bacterial pathogens were isolated from 508 patients. Co-infection of bacteria was not detected in any of the cases. Salmonella spp. accounted for $42.2 \%$ of the detected bacterial pathogens, followed by
DEC 23.5 \%, Campylobacter spp. 14.7 \%, Aeromonas spp. $9.8 \%$ and Shigella spp. $5.9 \%$. No Vibrio cholerae and Plesiomonas spp. were isolated from the 508 samples (Fig. 2). All of the Campylobacter spp. was confirmed to be C. jejuni by PCR. The 43 strains of Salmonella spp. detected were distributed among 10 serotypes, with $S$. Typhimurium $(\mathrm{O} 4 \mathrm{Hi})$ being the predominant serotype identified (18/43, $41.9 \%)$. Among 24 strains of DEC, 11 strains of EPEC, 10 strains of STEC and three strains of EAEC were confirmed by PCR typing. Of the six strains of Shigella spp., four were S. flexneri and two were S. sonnei as determined by serum agglutination assays (Table 1).

\section{Antimicrobial resistance}

Of the 43 strains of Salmonella spp. detected, more than $60 \%$ were resistant to ampicillin and tetracycline. The resistance rates to co-trimoxazole and azithromycin were $>40 \%$ and to chloramphenicol was $>30 \%$, for all other antibiotics tested the rates were $<30 \%$. For DEC, the highest resistance rate of $>60 \%$ was detected for ampicillin and tetracycline, followed by $50 \%$ for cefotaxime, then $>30 \%$ for ampicillin/sulbactam, ciprofloxacin, chloramphenicol, cefuroxime and gentamycin, and $<30 \%$ for levofloxacin, amikacin and imipenem. Among the 15 strains of C. jejuni detected, nine strains showed resistance to ciprofloxacin and one strain was resistant to azithromycin; the strains were sensitive to all other antibiotics tested. Among the 10 strains of Aeromonas spp., five strains were resistant to cefazolin, four to tetracycline, and three to cefotaxime (Fig. 3). Drug sensitivity tests were not performed for Shigella spp., Vibrio parahaemolyticus and Yersinia enterocolitica

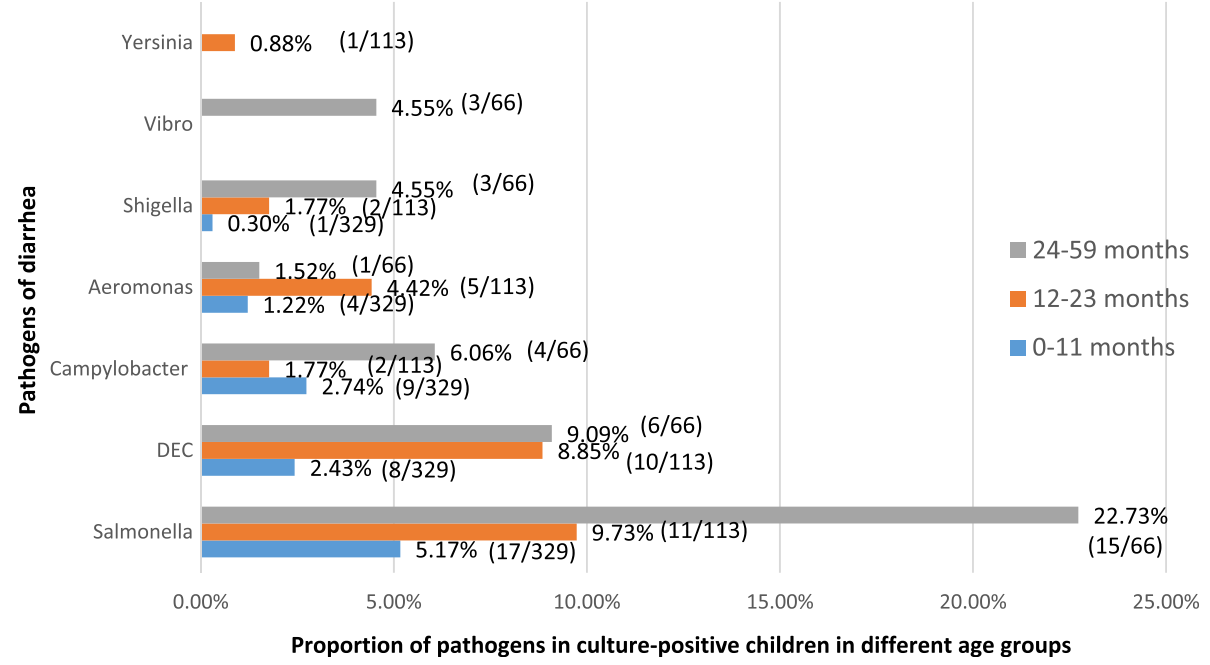

Fig. 2 Frequency distribution of bacterial pathogens isolated from stool samples of 508 patients with acute diarrhea according to age group. The bars showed the percentage of the pathogens in culture-positive children in different age groups 
Table 1 Serotype distribution of Salmonella, DEC, Shigella and other bacterial pathogens isolated from acute diarrheal patients

\begin{tabular}{|c|c|c|}
\hline \multirow{2}{*}{\multicolumn{2}{|c|}{$\begin{array}{l}\text { Pathogens } \\
\text { Salmonella spp. }\end{array}$}} & \multirow{2}{*}{$\frac{\text { No. of isolates }}{43 / 508(8.5 \%)}$} \\
\hline & & \\
\hline & $\mathrm{O} 4 \mathrm{Hi}$ & 18/43(41.9 \%) \\
\hline & $\mathrm{O} 4 \mathrm{Hb}$ & $6 / 43(14.0 \%)$ \\
\hline & $\mathrm{O} H \mathrm{Hd}$ & 4/43(9.3\%) \\
\hline & $\mathrm{O} 4 \mathrm{Hf}$ & 3/43(7.0 \%) \\
\hline & $\mathrm{O} 4 \mathrm{Hd}$ & $3 / 43(7.0 \%)$ \\
\hline & O7Hk & 3/43(7.0 \%) \\
\hline & $\mathrm{O} 7 \mathrm{Hf}$ & $2 / 43(4.7 \%)$ \\
\hline & $\mathrm{O} 7 \mathrm{Hr}$ & $2 / 43(4.7)$ \\
\hline & $\mathrm{O} 4 \mathrm{Hh}$ & $1 / 43(2.2 \%)$ \\
\hline & $\mathrm{O} 2 \mathrm{Ha}$ & $1 / 43(2.2 \%)$ \\
\hline \multirow[t]{6}{*}{ DEC } & & 24/508(47.2 \%) \\
\hline & EPEC & $11 / 24(45.8 \%)$ \\
\hline & STEC & 10/24(41.7\%) \\
\hline & EAEC & $3 / 24(12.5 \%)$ \\
\hline & EIEC & 0 \\
\hline & ETEC & 0 \\
\hline \multicolumn{2}{|c|}{ Campylobacter spp } & 15/508(3.0 \%) \\
\hline & Campylobacter jejuni & 15/15(100 \%) \\
\hline \multicolumn{2}{|l|}{ Aeromonas spp } & 10/508(19.7\%) \\
\hline & Aeromonas hydrophila & 8/10(80 \%) \\
\hline & Aeromonas sobria & $1 / 10(10 \%)$ \\
\hline & Aeromonas veronii & $1 / 10(10 \%)$ \\
\hline \multirow[t]{3}{*}{ Shigella spp. } & & $6 / 508(1.2 \%)$ \\
\hline & S. flexneri & $4 / 6(66.7 \%)$ \\
\hline & S. sonnei & 2/6 (33.3\%) \\
\hline \multirow[t]{2}{*}{ Vibrio spp } & & $3 / 508(0.6 \%)$ \\
\hline & Vibrio parahaemolyticus & $3 / 3(100 \%)$ \\
\hline \multirow[t]{2}{*}{ Yersinia spp } & & $1 / 508(0.2 \%)$ \\
\hline & Yersinia enterocolitica & 1/1 (100\%) \\
\hline Vibro cholerae & & 0 \\
\hline Plesiomonas spp & & 0 \\
\hline
\end{tabular}

because the number of strains was too small $(<10)$ to provide interpretable results.

\section{Molecular analysis of plasmid-mediated quinolone resistance genes and ESBL genes}

Three isolates of Salmonella spp. were found to be highly resistant to ciprofloxacin or levofloxacin (MIC $\geq 32 \mu \mathrm{g} / \mathrm{mL}$ ), however, only one isolate possessed the gyrA gene. Twelve isolates of Salmonella spp. were found to be highly resistant to cefotaxime or ceftriaxone (MIC $\geq 32 \mu \mathrm{g} / \mathrm{mL}$ ), three of which possessed the TEM-1 and/or CTX-M-14 genes (Table 2).

\section{Discussion}

In this study, the most common pathogenic bacteria associated with acute diarrhea in children under 5 years of age were found to be Salmonella spp., followed by DEC, C. jejuni and Aeromonas spp. These results were not consistent with the GEMS report in sub-Saharan Africa and south Asia [1]. In the case-control studies presented in the GEMS report, Shigella was highly associated with cases of moderate-to-severe diarrhea, EPEC showed an intermediate association, whereas Salmonella and Campylobacter were detected at similar rates in patients with or without diarrhea [1]. In a community-based study on the pathogen-specific burden of diarrhea in developing countries, which included eight study sites in South America, Africa and Asia, Campylobacter exhibited the highest attributable burden of diarrhea in infants (0-11 months) [22]. This may be due to distinct social, economic and environmental factors in these regions.

It was well recognized that children under 5 years of age are susceptible as a population group to Salmonella infection [23]. Non-typhoidal Salmonella (NTS) is one of the most common bacterial pathogens of foodborne infectious diseases [24]. In our study, S. Typhimurium was the most common serotype identified among Salmonella isolates, which was in agreement with previously reported studies from Niger and Guangdong Province in China $[25,26]$. For the treatment of Salmonella, fluoroquinolones are commonly used among adults, and cephalosporins are used to treat children $[27,28]$. The resistance rates to fluoroquinolones and cephalosporins among Salmonella have been increasing. The MIC of NTS to ciprofloxacin increased from 0.125 to $1.0 \mu \mathrm{g} / \mathrm{ml}$ during 2003 to 2005 in Asian countries [29]. The rate of full susceptibility of $S$. typhi to antibiotics declined from $80 \%$ in 2002 to $28 \%$ in 2013 in Switzerland [30]. It is therefore clear that antimicrobial resistance among Salmonella has become a worldwide concern [31, 32].

In our study, the resistance rates of Salmonella spp. to first line therapeutic drugs were high, i.e., $67.6 \%$ to ampicillin, $38.2 \%$ to chloramphenicol and $50 \%$ to cotrimoxazole. These results were consistent with a report from Niger, where the resistant rates to amoxicillin and co-trimoxazole were $>50 \%$ for Salmonella spp. [26]. For quinolones and cephalosporins, we detected higher resistance rates among Salmonella spp. than those reported from other regions of the world [25, 33, 34]. This finding may be related to the wide use of cephalosporin and quinolone antibiotics in China. By molecular analysis, we identified the ESBL genes TEM-1 and CTX-M-14 as the genetic determinants responsible for resistance to cephalosporins, and mutations in the plasmid-mediated quinolone resistance gene gyrA as the major determinant of resistance to quinolone antibiotics. 


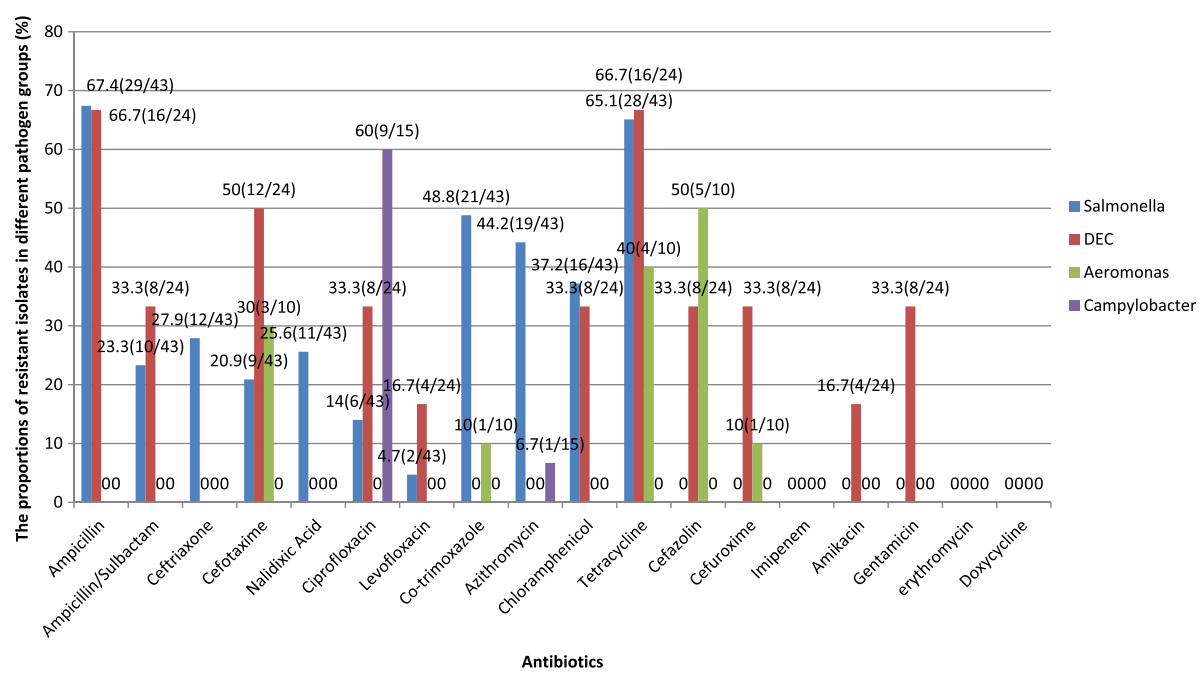

Fig. 3 Antibiotic resistance rate of Salmonalla, DEC, Aeromonas and Campylobacter. The bars showed the percentages of resistant isolates in culture-positive children in different pathogen groups

In our study, more than $50 \%$ of DEC isolates were resistant to ampicillin, cefotaxime and tetracycline, compared with $<20 \%$ for levofloxacin, amikacin and imipenem. This finding indicated that ampicillin, cefotaxime and tetracycline should not be used as first line defense against DEC infection, and that levofloxacin and amikacin might provide effective alternatives. Although most enteric infections caused by Campylobacter are self-limiting and do not require antibiotics, antibiotics are urgently required for prophylaxis in cases of acute diarrhea in immunocompromised patients and young children. Macrolides are recommended as the first choice therapy, with fluoroquinolones offering an effective alternative. In our study, with the exception of high ciprofloxacin resistance (60\%), Campylobacter isolates were sensitive to all other antibiotics tested. In a 17-year study in China, the proportion of quinolone-resistant isolates of Campylobacter was found to have increased markedly and reached 93.7-100\% after 2000 [35]. Similar high levels of quinolone-resistant Campylobacter isolates (97\% in 2008-2010) were reported in India [36]. The high prevalence of resistance to quinolones might be due to their overuse in food-producing animals [35].
This study had several limitations. It was not designed to assess attributable fractions, owing to restrictions on time and resources. In addition, the severity of diarrhea was not assessed, which may mean that milder episodes of diarrhea may have been overlooked.

\section{Conclusions}

Our findings indicated the wide range of bacteria responsible for acute diarrhea in children under 5 years of age, including Salmonella, Shigella, DEC, Campylobacter, Aeromonas, Vibrio parahaemolyticus and Yersinia enterocolitica. In this particular geographical region (central China), the most commonly isolated bacterial pathogen in young children with acute diarrhea was Salmonella spp., and S. Typhimurium was the most common serotype isolated. Antimicrobial susceptibility screening indicated that ampicillin and co-trimoxazole should not be used as the first line therapeutic drugs for Salmonella spp. In isolates of Salmonella spp. exhibiting cephalosporin and quinolone resistance, the TEM-1 and CTX-M-14 genes, and gyrA mutations, were identified as the resistance mechanisms, respectively.

Table 2 Characteristics of 3 Salmonella spp. isolates displaying non-wild-type phenotypes high resistant to cephalosporins and quinolones

\begin{tabular}{|c|c|c|c|c|c|c|c|}
\hline \multirow{2}{*}{\multicolumn{2}{|c|}{ Isolate }} & \multicolumn{3}{|c|}{ Decreased susceptibility (MIC:ug/ml) } & \multicolumn{3}{|l|}{ Gentic profile } \\
\hline & & \multicolumn{2}{|c|}{ Cephalosporins } & \multicolumn{2}{|l|}{ Quinolones } & \multirow[b]{2}{*}{ Bla gene } & \multirow[b]{2}{*}{ PMQR gene } \\
\hline No & $\overline{C e f t r i a x o n e}$ & Cefotaxime & Ciprofloxacin & Levofloxacin & Nalidixic acid & & \\
\hline 1 & 4 & 32 & 64 & 64 & 64 & TEM-1 & - \\
\hline 2 & 1 & 32 & 64 & 8 & 64 & CTX-M-14 & - \\
\hline 3 & 128 & 32 & 64 & 1 & 64 & TEM-1,CTX-M-14 & gyr A \\
\hline
\end{tabular}




\section{Abbreviations}

CCDA, cefoperazone deoxycholate agar; CLSI, clinical and laboratory standards institute; DEC, Diarrheogenic Escherichia coli; EAEC, Enteroaggregative E. coli; EIEC, Enteroinvasive E. coli; EPEC, Enteropathogenic E. Coli; ESBL, extended-spectrum ß-lactamase; ETEC, Enterotoxigenic E. coli; GEMS, global enteric multicenter study; MAC, macconkey agar; MIC, minimum inhibitory concentration; MNQR, plasmid-mediated quinolone resistance; NTS, non-typhoidal Salmonella; PCR polymerase chain reaction; SBG, sulfa enrichment broth; STEC, Shiga-toxinproducing E. coli; TCBS, thiosulfate-citrate-bilesalts-sucrose; XLD, xylose lysine desoxycholate medium

\section{Acknowledgments}

We thank Jianmao Wang, Feng Wang and Na Shen for their help in map construction and data analyses.

\section{Funding}

This work was supported by the Infectious Diseases Control Project from Ministry of Health of China Grant (2012ZX10004-207). The funders had no role in study design, data collection and analysis, decision to publish, or preparation of the manuscript.

\section{Availability of data and materials}

All data is contained within the manuscript. Clinical isolates will be made available upon requests from Dr. Ziyong Sun.

\section{Authors' contributions}

ZS designed the study. SL, WY, WZ and XX were responsible for recruitment, interview of the patients, samples collection and transport to the laboratory. ZC and WL were in charge of laboratory procedures. XZ did the statistical analysis. LT, XZ and WL wrote the manuscript. All authors read and approved the final manuscript.

\section{Competing interests}

The authors declare that they have no competing interests.

\section{Consent for publication}

Not applicable.

\section{Ethics approval and consent to participate}

The study protocol was approved by the Tongji Hospital ethics committee for research in health. Informed written consent was obtained from the parents or legal guardian of the patient before inclusion in the study.

\section{Received: 28 January 2016 Accepted: 27 May 2016}

\section{Published online: 07 June 2016}

\section{References}

1. Kotloff KL, Nataro JP, Blackwelder WC, Nasrin D, Farag TH, Panchalingam S, Wu Y, Sow SO, Sur D, Breiman RF, et al. Burden and aetiology of diarrhoea disease in infants and young children in developing countries (the Global Enteric Multicenter Study, GEMS): a prospective, case-control study. Lancet 2013;382(9888):209-22.

2. Lanata CF, Fischer-Walker CL, Olascoaga AC, Torres CX, Aryee MJ, Black RE, Child Health Epidemiology Reference Group of the World Health O, Unicef et al. Global causes of diarrheal disease mortality in children $<5$ years of age: a systematic review. PLoS One. 2013;8(9):e72788.

3. Liu L, Johnson HL, Cousens S, Perin J, Scott S, Lawn JE, Rudan I, Campbell H, Cibulskis R, Li M, et al. Global, regional, and national causes of child mortality: an updated systematic analysis for 2010 with time trends since 2000. Lancet. 2012;379(9832):2151-61.

4. Panchalingam S, Antonio M, Hossain A, Mandomando I, Ochieng B, Oundo J, Ramamurthy T, Tamboura B, Zaidi AK, Petri W, et al. Diagnostic microbiologic methods in the GEMS-1 case/control study. Clin infect dis: off publ Infect Dis Soc Am. 2012:55 Suppl 4:S294-302.

5. Nasrin D, Wu Y, Blackwelder WC, Farag TH, Saha D, Sow SO, Alonso PL, Breiman RF, Sur D, Faruque AS, et al. Health care seeking for childhood diarrhea in developing countries: evidence from seven sites in Africa and Asia. AmJTrop Med Hyg. 2013;89(1 Suppl):3-12.

6. Levine MM, Kotloff KL, Nataro JP, Muhsen K. The Global Enteric Multicenter Study (GEMS): impetus, rationale, and genesis. Clin infect dis: off publ Infect Dis Soc Am. 2012;55 Suppl 4:S215-24
7. Kotloff KL, Blackwelder WC, Nasrin D, Nataro JP, Farag TH, van Eijk A, Adegbola RA, Alonso PL, Breiman RF, Faruque AS, et al. The Global Enteric Multicenter Study (GEMS) of diarrheal disease in infants and young children in developing countries: epidemiologic and clinical methods of the case/ control study. Clin infect dis: off publ Infect Dis Soc Am. 2012;55 Suppl 4:S232-45.

8. Walker CLF, Rudan I, Liu L, Nair H, Theodoratou E, Bhutta ZA, O'Brien KL, Campbell H, Black RE. Global burden of childhood pneumonia and diarrhoea. Lancet. 2013;381(9875):1405-16.

9. Vasco G, Trueba G, Atherton R, Calvopina M, Cevallos W, Andrade T, Eguiguren M, Eisenberg JN. Identifying etiological agents causing diarrhea in low income Ecuadorian communities. AmJTrop Med Hyg. 2014:91(3):563-9.

10. Yu J, Jing H, Lai S, Xu W, Li M, Wu J, Liu W, Yuan Z, Chen Y, Zhao S, et al. Etiology of diarrhea among children under the age five in China: Results from a five-year surveillance. J infect. 2015;71(1):19-27.

11. Sanchez-Capilla AD, Sorlozano-Puerto A, Rodriguez-Granger J, Martinez-Brocal A, Navarro-Mari JM, Gutierrez-Fernandez J. Infectious etiology of diarrheas studied in a third-level hospital during a five-year period. Rev Esp Enferm Dig: organo ofic Soc Esp Patol Dig. 2015;107(2):89-97.

12. Bicer S, Col D, Erdag GC, Giray T, Gurol Y, Yilmaz G, Vitrinel A, Ozelgun B. A retrospective analysis of acute gastroenteritis agents in children admitted to a university hospital pediatric emergency unit. Jundishapur j microbiol. 2014;7(4):e9148

13. Wang X, Wang J, Sun H, Xia S, Duan R, Liang J, Xiao Y, Qiu H, Shan G, Jing $H$. Etiology of Childhood Infectious Diarrhea in a Developed Region of China: Compared to Childhood Diarrhea in a Developing Region and Adult Diarrhea in a Developed Region. PLoS One. 2015;10(11):e0142136.

14. Davidson G, Barnes G, Bass D, Cohen M, Fasano A, Fontaine O, Guandalini S. Infectious diarrhea in children: Working Group Report of the First World Congress of Pediatric Gastroenterology, Hepatology, and Nutrition. J Pediatr Gastroenterol Nutr. 2002;35 Suppl 2:S143-50.

15. Muhsen $\mathrm{K}$, Levine MM. A systematic review and meta-analysis of the association between Giardia lamblia and endemic pediatric diarrhea in developing countries. Clin infect dis: off publ Infect Dis Soc Am. 2012:55 Suppl 4:S271-93.

16. Denis M, Soumet C, Rivoal K, Ermel G, Blivet D, Salvat G, Colin P. Development of a m-PCR assay for simultaneous identification of Campylobacter jejuni and C. coli. Lett Appl Microbiol. 1999;29(6):406-10.

17. Linton D, Lawson AJ, Owen RJ, Stanley J. PCR detection, identification to species level, and fingerprinting of Campylobacter jejuni and Campylobacter coli direct from diarrheic samples. J Clin Microbiol. 1997:35(10):2568-72.

18. Kagambega A, Martikainen O, Lienemann T, Siitonen A, Traore AS, Barro N, Haukka K. Diarrheagenic Escherichia coli detected by 16-plex PCR in raw meat and beef intestines sold at local markets in Ouagadougou, Burkina Faso. Int J Food Microbiol. 2012;153(1-2):154-8.

19. Tobias J, Vutukuru SR. Simple and rapid multiplex PCR for identification of the main human diarrheagenic Escherichia coli. Microbiol Res. 2012;167(9):564-70.

20. Clinical and Laboratory Standards Institute. Performance Standards for Antimicrobial Susceptibility Testing, Twenty-fifth Informational Supplement, M100-S25. Wayne, PA: Clin Lab Stand Institute; 2015.

21. Kao CY, Chen CA, Liu YF, Wu HM, Chiou CS, Yan JJ, Wu JJ. Molecular characterization of antimicrobial susceptibility of Salmonella isolates: First identification of a plasmid carrying qnrD or oqxAB in Taiwan. J microbiol immunol infect. 2015. DOl:10.1016/j.jmii.2015.03.004.

22. Platts-Mills JA, Babji S, Bodhidatta L, Gratz J, Haque R, Havt A, McCormick BJ, McGrath M, Olortegui MP, Samie A, et al. Pathogen-specific burdens of community diarrhoea in developing countries: a multisite birth cohort study (MAL-ED). Lancet Global health. 2015;3(9):e564-75.

23. Scallan E, Mahon BE, Hoekstra RM, Griffin PM. Estimates of illnesses, hospitalizations and deaths caused by major bacterial enteric pathogens in young children in the United States. Pediatr Infect Dis J. 2013;32(3):217-21.

24. Galanis E, Lo Fo Wong DM, Patrick ME, Binsztein N, Cieslik A, Chalermchikit T, Aidara-Kane A, Ellis A, Angulo FJ, Wegener HC, et al. Web-based surveillance and global Salmonella distribution, 2000-2002. Emerg Infect Dis. 2006;12(3):381-8.

25. Liang Z, Ke B, Deng X, Liang J, Ran L, Lu L, He D, Huang Q, Ke C, Li Z et al. Serotypes, seasonal trends, and antibiotic resistance of non-typhoidal Salmonella from human patients in Guangdong Province, China, 2009-2012. BMC Infect Dis. 2015;15:53. 
26. Langendorf C, Le Hello S, Moumouni A, Gouali M, Mamaty AA, Grais RF, Weill FX, Page AL. Enteric bacterial pathogens in children with diarrhea in Niger: diversity and antimicrobial resistance. PLoS One. 2015;10(3):e0120275.

27. Sjolund-Karlsson M, Folster JP, Pecic G, Joyce K, Medalla F, Rickert R, Weill FX, Page AL. Emergence of plasmid-mediated quinolone resistance among non-Typhi Salmonella enterica isolates from humans in the United States. Antimicrob Agents Chemother. 2009;53(5):2142-4.

28. Sjolund-Karlsson M, Rickert R, Matar C, Pecic G, Howie RL, Joyce K, Medalla F, Barzilay EJ, Whichard JM. Salmonella isolates with decreased susceptibility to extended-spectrum cephalosporins in the United States. Foodborne Pathog Dis. 2010;7(12):1503-9.

29. Lee HY, Su LH, Tsai MH, Kim SW, Chang HH, Jung SI, Park KH, Perera J, Carlos C, Tan BH, et al. High rate of reduced susceptibility to ciprofloxacin and ceftriaxone among nontyphoid Salmonella clinical isolates in Asia. Antimicrob Agents Chemother. 2009;53(6):2696-9.

30. Nuesch-Inderbinen M, Abgottspon H, Sagesser G, Cernela N, Stephan R. Antimicrobial susceptibility of travel-related Salmonella enterica serovar Typhi isolates detected in Switzerland (2002-2013) and molecular characterization of quinolone resistant isolates. BMC Infect Dis. 2015;15:212.

31. Helms M, Ethelberg S, Molbak K, Group DTS. International Salmonella Typhimurium DT104 infections, 1992-2001. Emerg Infect Dis. 2005:11(6):859-67.

32. Su LH, Chiu CH, Chu C, Ou JT. Antimicrobial resistance in nontyphoid Salmonella serotypes: a global challenge. Clin infect dis: off publ Infect Dis Soc Am. 2004;39(4):546-51.

33. Thompson CN, Phan MV, Hoang NV, Minh PV, Vinh NT, Thuy CT, Nga TT, Rabaa MA, Duy PT, Dung TT, et al. A prospective multi-center observational study of children hospitalized with diarrhea in Ho Chi Minh City, Vietnam. AmJTrop Med Hyg. 2015;92(5):1045-52.

34. Saeed A, Abd H, Sandstrom G. Microbial aetiology of acute diarrhoea in children under five years of age in Khartoum, Sudan. J Med Microbiol. 2015; 64(Pt 4):432-7.

35. Zhou J, Zhang M, Yang W, Fang Y, Wang G, Hou F. A seventeen-year observation of the antimicrobial susceptibility of clinical Campylobacter jejuni and the molecular mechanisms of erythromycin-resistant isolates in Beijing, China. Int j infect dis: IJID : off publ Int Soc Infect Dis. 2016;42:28-33.

36. Mukherjee P, Ramamurthy T, Bhattacharya MK, Rajendran K, Mukhopadhyay AK. Campylobacter jejuni in hospitalized patients with diarrhea, Kolkata, India. Emerg Infect Dis. 2013;19(7):1155-6.

\section{Submit your next manuscript to BioMed Central and we will help you at every step:}

- We accept pre-submission inquiries

- Our selector tool helps you to find the most relevant journal

- We provide round the clock customer support

- Convenient online submission

- Thorough peer review

- Inclusion in PubMed and all major indexing services

- Maximum visibility for your research

Submit your manuscript at www.biomedcentral.com/submit

) Biomed Central 